\section{El campo jurídico como mercado educativo en la Universidad Autónoma del Estado de Hidalgo}

The legal field as an educational market at Universidad Autónoma del Estado de Hidalgo

Claudia Valeria Zúñiga Manríquez; Armando Ulises Cerón Martínez

\section{RESUMEN}

Oferta y demanda provocan tensiones bajo las cuales se llevan a cabo la producción y la adquisición de bienes valuados. La investigación se enmarca por la Teoría de la Economía de las Prácticas Sociales de Pierre Bourdieu, la misma que concibe al derecho como un mercado productor de diversos capitales como lo son el capital jurídico y el político, pero además el capital burocrático en un nivel alto de importancia. La metodología configurada para este trabajo es complementaria, conforme la cual se hizo uso de información objetiva del campo, estadísticas institucionales y aplicación de cuestionarios a estudiantes de los dos subcampos identificados, el de Licenciatura en Derecho y el de posgrado, el programa de Maestría en Derecho Penal y Ciencias Penales del Instituto de Ciencias Sociales y Humanidades de la Universidad Autónoma del Estado de Hidalgo. Asimismo, se realizaron entrevistas semiestructuradas a Informantes Clave, para conocer con mayor profundidad el aspecto subjetivo de la realidad social estudiada. El mercado educativo del derecho conserva formas de pensamiento jurídico clásico, sin embargo, produce posiciones híbridas laborales, fenómenos endogámicos y pretensiones e intereses científicos que no se llevan a la práctica, lo cual devela necesidades de transformación e innovación del campo para adecuarse a la actualidad social.

Palabras clave: campo jurídico; mercado productor; capitales; disposiciones.

\section{ABSTRACT}

Supply and demand cause tensions under which the production and acquisition of valued goods takes place. The research is framed by Pierre Bourdieu's Theory of the Economy of Social Practices, the same one that conceives of law as a market that produces various capitals such as legal and political capital, but also bureaucratic capital at a high level of importance. Social production is, in terms of Bourdieu's theory, the generation of capitals and dispositions in a specific social field. The capitals are the resources or accumulated work that the agents possess according to the interests or inclinations of the same field. Dispositions are those ways of seeing the world, of thinking, feeling, acting or constructing reality that are internalized by the agents that actively intervene within the social field. Therefore, what I know it produces in the field, conceived as a market, in a certain way it reproduces itself there. Capitals and dispositions that the field requires or that are considered effective in it, due to their value as merchandise, prevail. The methodology configured for this work is complementary, according to which use was made of objective information from the field, institutional statistics and the application of questionnaires to students in the two identified subfields, the undergraduate program in Law and the graduate program, the Master's Degree in Criminal Law and Criminal Sciences of the Institute of Social Sciences and Humanities of the Autonomous University of the State of Hidalgo. Semi-structured interviews were also carried out with Key Informants to learn more about the subjective aspect of the social reality studied. The educational market of law preserves the forms of classical legal thought, however, it also produces hybrid work positions, endogamous phenomena, and teaching or scientific intentions, which reveals the needs of transformation and innovation of the field to adapt to the current social situation.

Keywords: law field; producer market; capitals; dispositions

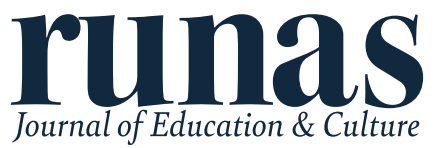

INFORMACIÓN:

http://doi.org/10.46652/runas.v2i4.49 ISSN $2737-6230$

Vol. 2, No. 4, 2021. e21049

Quito, Ecuador

Enviado: octubre 10, 2021

Aceptado: diciembre 02, 2021

Publicado: diciembre 11, 2021

Sección Dossier | Peer Reviewed

Publicación continua
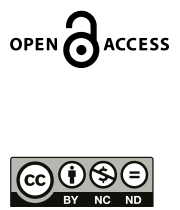

AUTORES:

Claudia Valeria Zúñiga Manríquez Universidad Autónoma del Estado de Hidalgo - México

claudia161895@uaeh.edu.mx

Armando Ulises Cerón Martínez Universidad Autónoma del Estado de Hidalgo - México

aceron@uaeh.edu.mx

\section{CONFLICTO DE INTERESES}

Los autores declaran que no existe conflicto de interés posible.

FINANCIAMIENTO

No existió asistencia financiera de partes externas al presente artículo. NOTA

El presente artículo se desprende de la tesis de maestría denominada "El mercado educativo del derecho en el Instituto de Ciencias Sociales y Humanidades de la Universidad Autónoma del Estado de Hidalgo" y del proyecto de investigación en proceso del Doctorado en Ciencias Sociales de la misma institución.

PUBLISHER 


\section{Introducción}

El presente artículo de investigación tiene como objetivo describir la forma bajo la cual se producen los recursos sociales, entendidos como capitales y disposiciones de los agentes que participan en el campo del Área Académica de Derecho y Jurisprudencia del Instituto de Ciencias Sociales y Humanidades (ICSHu) en la Universidad Autónoma del Estado de Hidalgo (UAEH). El fundamento teórico que enmarca la investigación es la Teoría de la Economía de las Prácticas Sociales de Pierre Bourdieu, en la cual se entienden estos insumos de los diferentes campos sociales como los recursos que se generan dado el valor social que tienen, en tanto los campos sociales son comprendidos como mercados, las disposiciones como habitus, así como los capitales son entendidos como mercancía.

El derecho, histórica y tradicionalmente ha sido un campo que se investiga con herramientas racionalistas y formalistas que lo conciben como un cuerpo estructurado que beneficia la vida social y, no se visibiliza, el aspecto reflexivo que develan intereses y juegos simbólicos trascendentales para su estudio (Becerra, 2020; Pezzeta, 2016).

La teoría de Pierre Bourdieu, la Economía de las Prácticas Sociales tiene una base estructuralistaconstructivista, desde la cual el espacio social se compone por la estructura y el volumen del capital, así como por la trayectoria del campo y sus agentes (Bourdieu, 2011).

El campo puede ser entendido como un espacio de fuerzas que se imprimen sobre las personas que ocupan dicho espacio. Las personas (agentes) actúan de manera diferente con respecto a su posición. El campo es un espacio de luchas que buscan transformar esas fuerzas con base en las reglas del juego y los capitales en disputa (Bourdieu, 1993). Las disputas que se llevan a cabo dentro del campo jurídico también muestran la violencia simbólica con la que se dice y practica el derecho (Moreno et al., 2019).

Para conocer la dinámica de formación jurídica se requiere trascender las posturas tradicionales del derecho, ya que estas permean en discursos, instituciones y formas de mirar al mundo social, político, económico y, por supuesto, jurídico (Wolkmer, 2019). Se indaga en el campo educativo del derecho para conocer y reconstruir la forma en que se poseen los capitales, como recursos valiosos en el campo y la manera de posicionarse ante los mismos.

Todo campo es equiparable a un mercado en que se producen y negocian diferentes recursos y que comprenden cuestiones sociales y culturales (Moyano, 2020). Dentro de los campos se privilegian las producciones que demanda el mismo espacio social, a través de sus agentes y de la lógica interna de funcionamiento de oferta y demanda.

El campo del poder se manifiesta también mediante la formación dentro del sistema educativo y resulta importante recurrir a estos espacios para comprender la dinámica del campo jurídico. En contra del positivismo jurídico, del derecho es un espacio de lucha y de ejercicio de poder que no corresponde a lo justo, lo neutral o lo universal que proyecta comúnmente la dimensión jurídica en la vida social (Merino, 2017). 
La producción social es, en términos de la teoría bourdiana, la generación de capitales y disposiciones en un campo social específico. Los capitales son los recursos o trabajo acumulado que poseen los agentes de acuerdo con los intereses o inclinaciones del mismo campo. Las disposiciones son las formas de ver el mundo, de pensar, sentir, actuar o construir la realidad que se encuentran interiorizadas por los agentes que intervienen activamente dentro del campo social. Por ello, lo que se produce en el campo, concebido como mercado, de cierta forma se reproduce ahí mismo. Prevalecen los capitales y las disposiciones que el campo requiere o que en él se consideran eficaces, por su valor como mercancía.

Existen muchos intereses diversos en el campo jurídico que no devienen del fin último del derecho como instrumento para el bienestar social, el mercado laboral o inclusive, las ofertas de empleo dentro del mundo económico guían la toma de decisiones de quienes se forman en el ramo profesional del derecho (Gómez, 2016).

Algunos de los aspectos más interesantes de la investigación indican que el mercado educativo del derecho tiene una producción activa y elevada del capital simbólico del derecho, el capital jurídico que alimenta la práctica postulante privada y que se enlaza directamente con el capital burocrático, siendo también el capital político que sirve como material simbólico que se manifiesta en las disposiciones de agentes, quienes no se dedican a la política pero discursivamente expresan intereses de esta índole.

\section{Metodología}

Diversos autores como Peter Berger, Thomas Luckman, Hugo Zemelman y Pierre Bourdieu, han postulado la exigencia en investigación social de la metodología que vincule el aspecto objetivo y el subjetivo (Torres y Jiménez, 2006). La investigación realizada se adscribe a dichas consideraciones en el entramado epistemológico-metodológico.

La metodología aplicada en la investigación, en un primer momento, busca esbozar la estructura del campo, la lógica de su funcionamiento y posteriormente las relaciones entre los agentes singulares a través de sus trayectorias personales y percepciones (Bourdieu, 2002).

En el caso específico de esta investigación se ha hecho una aproximación documental y empírica para conocer el campo jurídico estudiado, el Área Académica de Derecho y Jurisprudencia de la UAEH en el ICSHu, con el propósito de conocer las posiciones existentes y las características de estas, así como la trayectoria del área.

En un segundo momento de la investigación se exploraron las disposiciones interiorizadas de los agentes del campo, así como sus consideraciones personales a través de entrevistas semiestructuradas a 10 Informantes Clave (IC) que fueron seleccionados con base en su pertenencia al campo jurídico del ICSHu y el subcampo con el cual tienen mayor relación (campo docente, jurídico, científico o burocrático). 
Se realizó la aplicación de cuestionarios en los dos subcampos del Área Académica de Derecho y Jurisprudencia, 19 estudiantes de la Licenciatura en Derecho (LD) y 28 estudiantes de la Maestría en Derecho Penal y Ciencias Penales (MDPCP).

Se aplicaron 10 entrevistas semiestructuradas a Informantes Clave (IC), tomando como criterio para su selección el egreso de la Licenciatura en Derecho (LD) en el ICSHu y en algunos casos el hecho de encontrarse trabajando como docentes o estudiando el posgrado dentro del campo. La característica principal de los IC es su pertenencia al mercado educativo desde diversos campos de intersección (docente, científico, jurídico o burocrático).

La metodología que propone Bourdieu implica un proceso reflexivo crítico en el cual se realiza una ruptura epistemológica que también resulta ser una ruptura de tipo social, estas rupturas generan, en muchas ocasiones, desacuerdos con las nociones compartidas por los grupos sociales en los cuales se investiga (Rosa, 2009).

Como ya se ha mencionado, las técnicas utilizadas en la construcción de la investigación fueron: la documental que integra las cuestiones institucionales que colaboran con la descripción de la estructura objetiva del campo social, el cuestionario para recabar información cuantitativa y cualitativa de los agentes del campo y la entrevista semiestructurada mediante la cual se obtuvo la información subjetiva, formas de pensar, sentir y actual, así como información de las trayectorias sociales de los agentes entrevistados.

\section{Resultados}

Se realizó el análisis de los datos basados en la aplicación de los cuestionarios y entrevistas. A continuación, se muestran algunos aspectos que destacan en los resultados.

\subsection{Características generales de los participantes de la investigación}

Los siguientes datos son los registros que se obtuvieron de la aplicación de cuestionarios. De los estudiantes de la LD el $73.68 \%$ son mujeres y el $26.31 \%$ son hombres, a distinción de los estudiantes de la MDPCP, en donde un $57.14 \%$ son mujeres y un $42.85 \%$ son hombres. De esta manera puede advertirse en la Figura 1 y 2 , respectivamente.

Figura 1. Sexo LD..

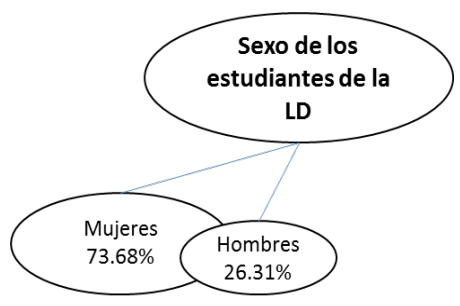

Fuente: Elaboración propia 
Figura 2. Sexo MDPCP.

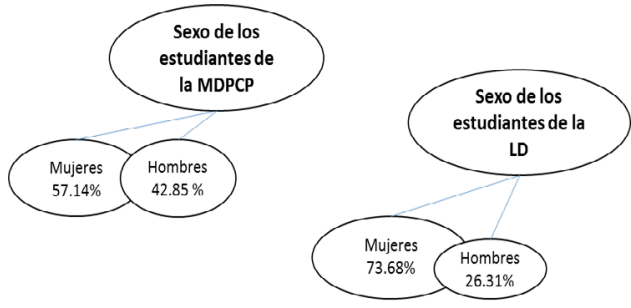

Fuente: Elaboración propia.

Las edades de los estudiantes de la LD, el número porcentual más representativo se encuentra en los 22 años con un 42.10\%, acorde con el ciclo escolar que les corresponde, a la edad de 21 años le corresponde el $31.57 \%$, también en concordancia con el ciclo escolar; existe un $10.52 \%$ de 24 años, un 5.26\% de 26 años y el mismo porcentaje de 5.26\% que no respondió la pregunta. Lo que puede apreciarse en la Tabla 1.

Tabla 1. Edades LD.

\begin{tabular}{|l|l|}
\hline \multicolumn{2}{|c|}{ Edades de estudiantes de la LD } \\
\hline Edad en años & Porcentaje \\
\hline 21 & $31.57 \%$ \\
\hline 22 & $42.10 \%$ \\
\hline 23 & $5.26 \%$ \\
\hline 24 & $10.52 \%$ \\
\hline 26 & $5.26 \%$ \\
\hline No contestó & $5.26 \%$ \\
\hline
\end{tabular}

Fuente: Elaboración propia.

Las edades de quienes se encuentran cursando el posgrado, Maestría en Derecho Penal y Ciencias Penales (MPCPD) no distan demasiado de los estudiantes de la LD, un $26.31 \%$ tiene 30 años, un 14.28\% tiene 25 años, $10.71 \% 27$ años y el mismo porcentaje 28 años. Las edades de 24, 26, 29 y 33 tienen, cada una, el porcentaje de $7.14 \%$ y las edades de 31 y 35 años, que es la edad más alta tienen $3.57 \%$ cada uno, el $3.57 \%$ no respondió a la pregunta. Como se puede observar en la Tabla 2.

Tabla 2. Edades MDPCP.

\begin{tabular}{|l|l|}
\hline \multicolumn{2}{|c|}{ Edades de estudiantes de la MDPCP } \\
\hline Edad en años & Porcentaje \\
\hline 24 & $7.14 \%$ \\
\hline 25 & $14.28 \%$ \\
\hline 26 & $7.14 \%$ \\
\hline 27 & $10.71 \%$ \\
\hline 28 & $10.71 \%$ \\
\hline 29 & $7.14 \%$ \\
\hline 30 & $26.31 \%$ \\
\hline 31 & $3.57 \%$ \\
\hline 33 & $7.14 \%$ \\
\hline 35 & $3.57 \%$ \\
\hline No contestó & $3.57 \%$ \\
\hline
\end{tabular}

Fuente: Elaboración propia. 
De acuerdo con el estado familiar de los estudiantes de la LD que fueron encuestados, se puede identificar un $\mathbf{9 4 . 7 3 \%}$ de estudiantes solteros y solamente un $5.26 \%$ en estado familiar de divorciado. En el caso de los estudiantes de la MDPCP el $75 \%$ es soltero, el $17.85 \%$ es casado y el $7.14 \%$ se encuentra en concubinato. Ambos grupos pueden observarse en la Figura 3 y 4 , respectivamente.

Figura 3. Estado familiar LD.

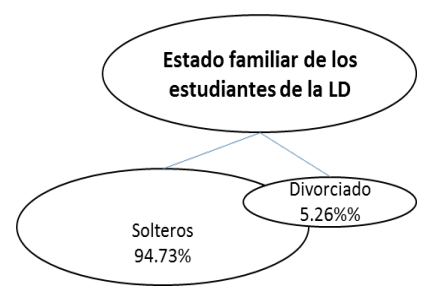

Fuente: Elaboración propia.

Figura 4. Estado familiar MDPCP.

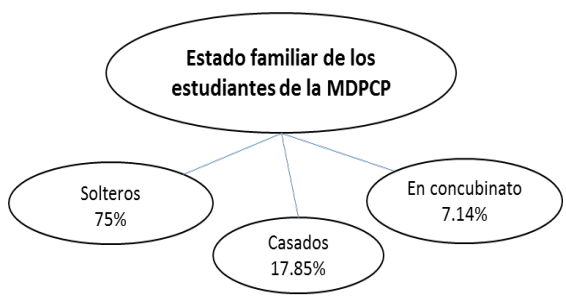

Fuente: Elaboración propia.

Dentro de la LD, los estudiantes que respondieron el cuestionario reportaron que el $42.10 \%$ vive con sus padres, el 31.75\% vive con compañeros de vivienda, el $10.52 \%$ vive sólo, el $5.26 \%$ con su madre, en el mismo porcentaje se encuentran quienes viven con sus amigos y con otros familiares. Lo que puede observarse en la Figura 5.

Figura 5. Personas con quienes viven LD.

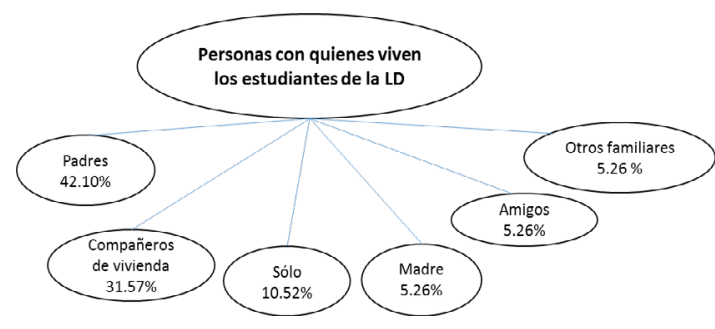

Fuente: Elaboración propia.

En el caso de la MDPCP el $46.42 \%$ vive con sus padres, el $25 \%$ vive con su familia propia; con otros familiares, el 10.71\%; el 7.14\%, con su madre, y el porcentaje de 3.57\% con amigos; en el mismo porcentaje se encuentran quienes viven solos y quienes viven con compañeros de vivienda. Como se advierte en la Figura 6. 
Figura 6. Personas con quienes viven MDPCP.

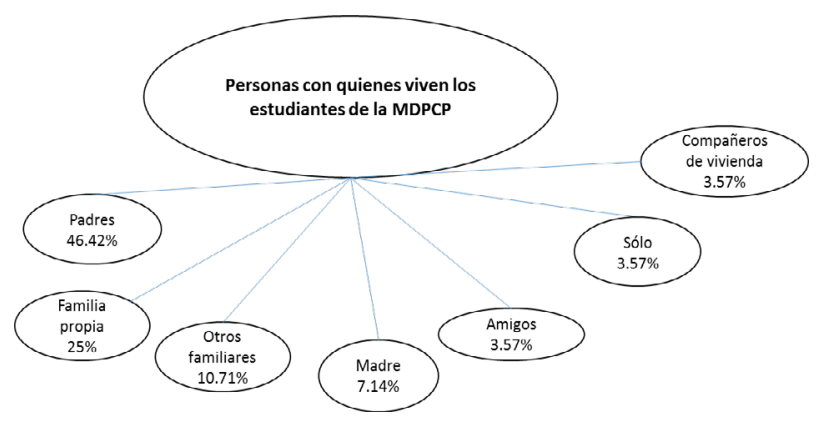

Fuente: Elaboración propia.

De acuerdo con los ingresos económicos familiares por mes de los estudiantes de la LD, el $42 \%$ se ubica en el rango de menos de $\$ 5000$ pesos mexicanos, el $26 \%$ corresponde al rango de $\$ 5$ ooo a $\$ 10$ ooo pesos, el $16 \%$ tiene un ingreso familiar entre $\$ 10$ ooo y $\$ 15$ ooo pesos, el $11 \%$ tiene un ingreso de $\$ 20$ ooo a $\$ 25000$ pesos y únicamente el $5 \%$ corresponde a un ingreso de $\$ 15000$ a \$20 ooo pesos. Así se muestra en el Gráfico 1.

Grafica 1. Ingresos económicos de estudiantes de la LD.

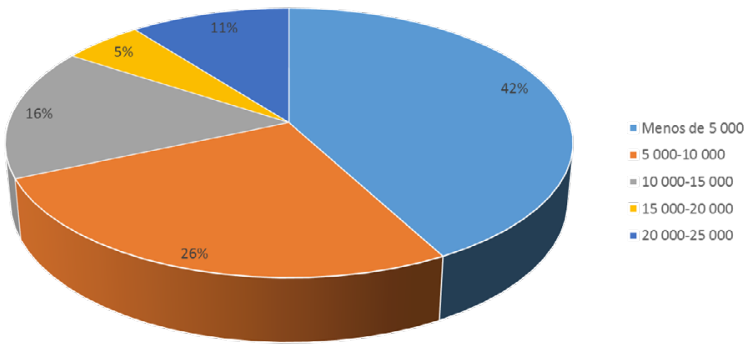

Fuente: Elaboración propia.

En tanto los ingresos económicos mensuales familiares de estudiantes de la MDPCP el 36\% corresponde a un ingreso familiar entre $\$ 15000$ y $\$ 20$ ooo pesos, el $22 \%$ corresponde a un ingreso de más de $\$ 25000$ pesos, el $14 \%$ corresponde a un ingreso entre $\$ 5000$ y $\$ 10$ ooo pesos, el $14 \%$ también corresponde a un ingreso entre $\$ 10$ ooo y $\$ 15$ ooo pesos mensuales y el mismo porcentaje es de quienes tienen como ingreso entre $\$ 20$ ooo y $\$ 25000$ pesos. Lo que puede apreciarse en el Gráfico 2.

Grafica 2. Ingresos económicos MDPCP.

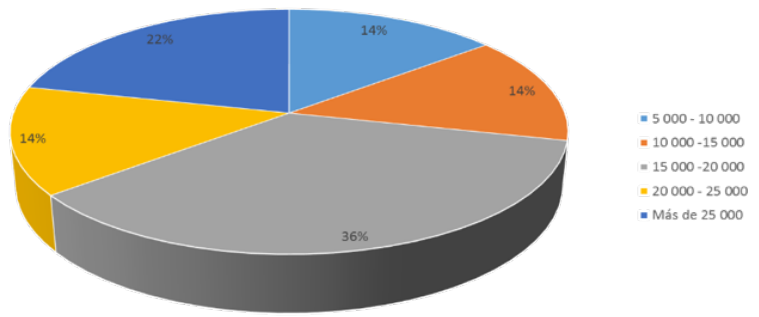

Fuente: Elaboración propia. 
De acuerdo con el municipio y entidad federativa en la cual nacieron los estudiantes de la LD, se puede notar que existe una preponderancia del estado de Hidalgo con un $68.4 \%$, como principal Entidad Federativa y a su vez, existe el mayor porcentaje para el municipio de Pachuca con un 47.36\%, seguido por el municipio de Tulancingo de Bravo con un $10.52 \%$ y posteriormente dos municipios con 5.26\% respectivamente, Xochicoatlán y Cuautepec de Hinojosa. Existe un 15.78\% de estudiantes que nacieron en el estado de México, de los cuales se observan los municipios de Otumba de Gómez Farías, Apaxco y Tlalnepantla de Baz, los tres con un 5.26\% cada uno. Un $15.78 \%$ de estudiantes que no respondieron la pregunta.

Tabla 3. Lugar de nacimiento LD.

\begin{tabular}{|c|c|c|}
\hline \multicolumn{3}{|c|}{ Estudiantes de la LD } \\
\hline $\begin{array}{l}\text { Municipio y Entidad Federativa de } \\
\text { nacimiento }\end{array}$ & Porcentaje & $\begin{array}{c}\text { Porcentaje por Entidad } \\
\text { Federativa }\end{array}$ \\
\hline Pachuca, Hidalgo & $47.36 \%$ & \multirow{4}{*}{$\begin{array}{l}\text { 68.4\% Estado de } \\
\text { Hidalgo }\end{array}$} \\
\hline Tulancingo de Bravo, Hidalgo & $10.52 \%$ & \\
\hline Xochicoatlán, Hidalgo & $5.26 \%$ & \\
\hline Cuautepec de Hinojosa, Hidalgo & $5.26 \%$ & \\
\hline Otumba de Gómez Farías, Estado de México & $5.26 \%$ & \multirow{3}{*}{$\begin{array}{l}15.78 \% \text { Estado de } \\
\text { México }\end{array}$} \\
\hline Apaxco, Estado de México & $5.26 \%$ & \\
\hline Tlalnepantla de Baz, Estado de México & $5.26 \%$ & \\
\hline No respondió & \multicolumn{2}{|c|}{$15.78 \%$} \\
\hline
\end{tabular}

Fuente: Elaboración propia

En el caso de los estudiantes de la LD se advierte que existe una mayoría con el $57.89 \%$ que se encuentra residiendo en la ciudad de Pachuca, un 26.31\% que viven en Mineral de la Reforma y un $5.26 \%$ que viven en Actopan, así como en Zempoala y Progreso. Como puede observarse en la Tabla 4.

Tabla 4. Lugar de residencia LD.

\begin{tabular}{|l|c|c|}
\hline \multicolumn{2}{|c|}{ Estudiantes de la LD } \\
\hline $\begin{array}{c}\text { Municipio y Entidad Federativa de } \\
\text { residencia }\end{array}$ & Porcentaje & $\begin{array}{c}\text { Porcentaje por } \\
\text { Entidad Federativa }\end{array}$ \\
\hline Pachuca, Hidalgo & $57.89 \%$ & \\
\hline Mineral de la reforma, Hidalgo & $26.31 \%$ & \multirow{2}{*}{$\begin{array}{c}\text { Hidalgo } \\
\text { Hctopán, Hidalgo }\end{array}$} \\
\cline { 1 - 2 } Zempoala, Hidalgo & $5.26 \%$ & \\
\hline Progreso, Hidalgo & $5.26 \%$ & \\
\hline
\end{tabular}

Fuente: Elaboración propia.

En el caso de la MDPCP no se nota mayor diferencia, inclusive hay un número mayor de personas que han nacido en la ciudad de Pachuca, existe una mayoría de $63.15 \%$ de este municipio, un 10.52\% originarios del municipio de Tulancingo de Bravo y un $7.14 \%$ perteneciente al municipio de Actopan, esto correspondiente al estado de Hidalgo. Originarios del estado de México, se 
encuentra el municipio de Naucalpan y Hueypoxtla ambos con un porcentaje de $5.26 \%$, del total de estudiantes de la MDPCP un $31.57 \%$ que no respondieron la pregunta. Como se puede advertir en la Tabla 5.

Tabla 5. Lugar de nacimiento MDPCP.

\begin{tabular}{|l|c|c|}
\hline \multicolumn{2}{|c|}{ Estudiantes de la MDPCP } \\
\cline { 1 - 2 } $\begin{array}{c}\text { Municipio y Entidad Federativa de } \\
\text { nacimiento }\end{array}$ & Porcentaje & $\begin{array}{c}\text { Porcentaje por Entidad } \\
\text { Federativa }\end{array}$ \\
\cline { 1 - 2 } Pachuca, Hidalgo & $63.15 \%$ & \multirow{2}{*}{ Estado de Hidalgo } \\
\cline { 1 - 2 } Tulancingo, Hidalgo & $10.52 \%$ & \\
\hline Tula de Allende, Hidalgo & $10.52 \%$ & \multirow{2}{*}{ Estado de México } \\
\hline Actopan, Hidalgo & $7.14 \%$ & \multicolumn{2}{|c}{$31.57 \%$} \\
\hline Naucalpan, Estado de México & $5.26 \%$ & \\
\cline { 1 - 2 } Hueypoxtla, Estado de México & $5.26 \%$ & \\
\cline { 1 - 2 } No respondió & \multicolumn{2}{|c|}{} \\
\hline
\end{tabular}

Fuente: Elaboración propia.

El estado de Hidalgo tiene el mayor porcentaje de los lugares de residencia de los estudiantes de la MDPCP con un $89.27 \%$, del total de los municipios en Pachuca, con $63.15 \%$, después el municipio de Tulancingo con un $10.52 \%$ y con el mismo porcentaje el municipio de Actopan y sigue Tula de Allende con un $3.57 \%$ y con ese mismo nivel porcentual se encuentran los municipios de Emiliano Zapata, Tasquillo e Ixmiquilpan.

Con un porcentaje de $3.57 \%$ cada uno, se encuentran Zumpango y Hueypoxtla, ambos municipios del estado de México y con el mismo porcentaje se encuentra Tantoyuca, municipio del estado de Veracruz. Se puede observar en la Tabla 6.

Tabla 6. Lugar de residencia MDPCP.

\begin{tabular}{|c|c|c|}
\hline \multicolumn{3}{|c|}{ Estudiantes de la MDPCP } \\
\hline $\begin{array}{l}\text { Municipio y Entidad Federativa de } \\
\text { residencia }\end{array}$ & Porcentaje & $\begin{array}{c}\text { Porcentaje por Entidad } \\
\text { Federativa }\end{array}$ \\
\hline Pachuca, Hidalgo & $53.57 \%$ & \multirow{8}{*}{$\begin{array}{c}\text { Estado de Hidalgo } \\
89.27 \%\end{array}$} \\
\hline Mineral de la Reforma, Hidalgo & $7.14 \%$ & \\
\hline Tulancingo, Hidalgo & $7.14 \%$ & \\
\hline Actopan, Hidalgo & $7.14 \%$ & \\
\hline Tula de Allende, Hidalgo & $3.57 \%$ & \\
\hline Emiliano Zapata, Hidalgo & $3.57 \%$ & \\
\hline Tasquillo, Hidalgo & $3.57 \%$ & \\
\hline Ixmiquilpan, Hidalgo & $3.57 \%$ & \\
\hline Zumpango, Estado de México & $3.57 \%$ & \multirow{2}{*}{$\begin{array}{c}\text { Estado de México } \\
7.14 \%\end{array}$} \\
\hline Hueypoxtla, Estado de México & $3.57 \%$ & \\
\hline Tantoyuca, Estado de Veracruz & $3.57 \%$ & $\begin{array}{c}\text { Estado de Veracruz } \\
3.57 \%\end{array}$ \\
\hline
\end{tabular}

Fuente: Elaboración propia. 


\subsection{Trayectoria escolar de los participantes y sus padres}

De acuerdo con la trayectoria escolar de los participantes de la investigación, particularmente en los estudiantes de la LD se recabó que únicamente el 5.26\% corresponde a quienes estudiaron educación primaria en escuela rural, el $94.73 \%$ lo hicieron en escuelas urbanas, asimismo ocurre en el caso de haber estudiado en escuelas privadas y religiosas.

En educación secundaria ocurre exactamente lo mismo porque únicamente el $5.26 \%$ estudió educación secundaria rural, privada y religiosa, mientras el $94.73 \%$ estudió en escuelas secundarias públicas, urbanas y laicas.

Tratándose de la educación inmediata anterior que es la educación media superior el 100\% de los participantes cursaron en escuelas urbanas, públicas y laicas. Lo que puede observarse en la Tabla 7.

Tabla 7. Trayectoria escolar LD.

\begin{tabular}{|c|c|c|}
\hline \multicolumn{2}{|c|}{ Trayectoria escolar de estudiantes de la LD } \\
\hline Primaria & Secundaria & Bachillerato \\
\hline $5.26 \%$ rural $/ 94.73 \%$ urbana & $5.26 \%$ rural $/ 94.73 \%$ urbana & $100 \%$ urbana \\
\hline $5.26 \%$ privada/94.73\% pública & $5.26 \%$ privada/94.73\% pública & $100 \%$ pública \\
\hline $5.26 \%$ religiosa / $94.73 \%$ laica & $5.26 \%$ religiosa $/ 94.73 \%$ laica & $100 \%$ laica \\
\hline
\end{tabular}

Fuente: Elaboración propia.

En el caso de los estudiantes de la MDPCP existe más variedad en las respuestas, el 32.14\% estudió educación primaria en escuela rural y un $67.85 \%$ lo hizo en escuela pública, el $25 \%$ estudió en escuela privada y el $75 \%$ corresponde a haber estudiado en escuela primaria pública, el 7.14\% estudió en escuela religiosa, siendo el 92.85\% quienes estudiaron en educación laica. La educación secundaria se estudió en un $25 \%$ en escuelas rurales y un $75 \%$ en urbanas, el $21.42 \%$ corresponde a educación privada y por lo tanto el 78.58\% en educación pública, únicamente el 7.14\% estudió la secundaria en escuela religiosa y el $92.85 \%$ en escuela laica. En educación media superior el 100\% se trató de escuelas urbanas, públicas y laicas. En el caso de educación superior, el nivel educativo inmediato anterior, el 100\% se trató de escuelas urbanas, el 17.85\% de escuelas privadas por lo que el $82.14 \%$ acudieron a escuela pública y el $3.57 \%$ estudió en escuela religiosa, siendo el $96.42 \%$ los que estudiaron en escuela laica. Lo anterior se puede observar en la Tabla 8.

Tabla 8. Trayectoria escolar MDPCP.

\begin{tabular}{|c|c|c|c|}
\hline \multicolumn{4}{|c|}{ Trayectoria escolar de estudiantes de la MDPCP } \\
\hline Primaria & Secundaria & Bachillerato & Educación Superior \\
\hline $\begin{array}{c}32.14 \% \text { rural / 67.85\% } \\
\text { urbana }\end{array}$ & $25 \%$ rural / 75\% urbana & $100 \%$ urbana & $100 \%$ urbana \\
\hline $\begin{array}{c}25 \% \text { privada/ } 75 \% \\
\text { pública }\end{array}$ & $\begin{array}{c}21.42 \% \text { privada/ } \\
78.58 \% \text { pública }\end{array}$ & $100 \%$ pública & $\begin{array}{c}17.85 \% \text { privada/ } \\
82.14 \% \text { pública }\end{array}$ \\
\hline $\begin{array}{c}7.14 \% \text { religiosa/ } \\
92.85 \% \text { laica }\end{array}$ & $\begin{array}{c}7.14 \% \text { religiosa / } \\
92.85 \% \text { laica }\end{array}$ & $100 \%$ laica & $3.57 \%$ religiosa/ $96.42 \%$ \\
laica
\end{tabular}

Fuente: Elaboración propia. 
En cuanto a la escolaridad de los padres de los estudiantes de la LD, particularmente en el caso de la escolaridad de la madre, el 26.31\% cuentan con educación primaria, el 21.05\% con educación media superior, el $15.78 \%$ con educación técnica, el mismo porcentaje cuentan con estudios superiores y el $10.52 \%$ cuenta con estudios de posgrado.

Con respecto a la escolaridad del padre de los estudiantes de la LD los registros indican que el 36.84\% cuentan con estudios de secundaria, el 21.05\% con estudios de educación superior, el $15.78 \%$ cuentan con educación media superior, el 5.26\% con educación primaria y el mismo porcentaje con educación de posgrado, un 10.25\% no respondió la pregunta. Lo anterior puede observarse en la Tabla 9.

Tabla 9. Escolaridad de madre LD.

\begin{tabular}{|l|c|}
\hline \multicolumn{2}{|c|}{\begin{tabular}{c} 
Escolaridad de padres de estudiantes de la LD \\
\hline $\begin{array}{c}\text { Nivel de estudios de su } \\
\text { madre }\end{array}$
\end{tabular}} \\
\hline Educación Primaria & $10.52 \%$ \\
\hline Educación Secundaria & $26.31 \%$ \\
\hline Educación Media Superior & $21.05 \%$ \\
\hline Educación Técnica & $15.78 \%$ \\
\hline Educación Superior & $15.78 \%$ \\
\hline Posgrado & $10.52 \%$ \\
\hline
\end{tabular}

Fuente: Elaboración propia.

En el caso de los estudiantes de la MDPCP, la escolaridad de su madre es en un 35.71\% de educación secundaria, sigue un $21.42 \%$ de educación primaria, un $14.28 \%$ de educación superior, un $10.71 \%$ de nivel técnico y $7.14 \%$ correspondiente a madres que tienen estudios de posgrado y el mismo porcentaje para madres que tienen educación media superior, únicamente el 3.57\% corresponde a quienes no tienen estudios académicos oficiales.

En cuanto al padre de los estudiantes de la MDPCP, se puede identificar que el $25 \%$ cuenta con el nivel de estudios medio superior, el 21.42\% cuenta con educación secundaria, el mismo porcentaje para quienes se cuentan con educación técnica, el 17.85\% cuenta con educación primaria y el 7.14\% con educación de posgrado. Únicamente el $3.57 \%$ no cuenta con estudios académicos oficiales.

Tabla 10. Escolaridad de madre MDPCP.

\begin{tabular}{|l|l|}
\hline \multicolumn{2}{|c|}{$\begin{array}{c}\text { Escolaridad de padres de estudiantes de la } \\
\text { MDPCP }\end{array}$} \\
\hline $\begin{array}{c}\text { Nivel de estudios de su } \\
\text { madre }\end{array}$ & Porcentaje \\
\hline Sin estudios & $3.57 \%$ \\
\hline Educación Primaria & $21.42 \%$ \\
\hline Educación Secundaria & $35.71 \%$ \\
\hline Educación Media Superior & $7.14 \%$ \\
\hline Educación Técnica & $10.71 \%$ \\
\hline Educación Superior & $14.28 \%$ \\
\hline Posgrado & $7.14 \%$ \\
\hline
\end{tabular}

Fuente: Elaboración propia. 
El caso de los estudiantes de la MDPCP es poco diferente, como se advierte la educación de las madres en un $35.71 \%$ es educación secundaria y la educación de los padres es media superior con un $25 \%$. Como puede observarse en la Tabla 10.

\subsection{Actividades y relaciones sociales de los participantes}

Acerca de las actividades recreativas que suelen llevar a cabo los estudiantes de la LD, se encuentra en primer lugar acudir a reuniones familiares, siguen las reuniones con amigos, el cine, los cafés, los museos, los festivales culturales, conciertos y bares, siendo las últimas actividades recreativas a las que dedican tiempo acudir a antros y al teatro. Lo que puede observarse en la Gráfica 3.

Grafica 3. Actividades recreativas LD.

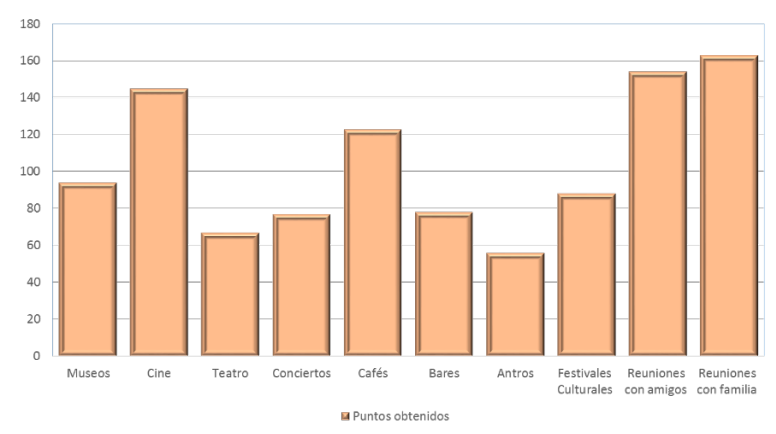

Fuente: Elaboración propia

En el tiempo libre los estudiantes de la LD reportan que en mayor medida dedican tiempo a leer libros, usar redes sociales, navegar en internet, practicar deporte, mirar la TV y en último lugar escuchar la radio. Como puede observarse en la Gráfica 4.

Grafica 4. Actividades tiempo libre LD.

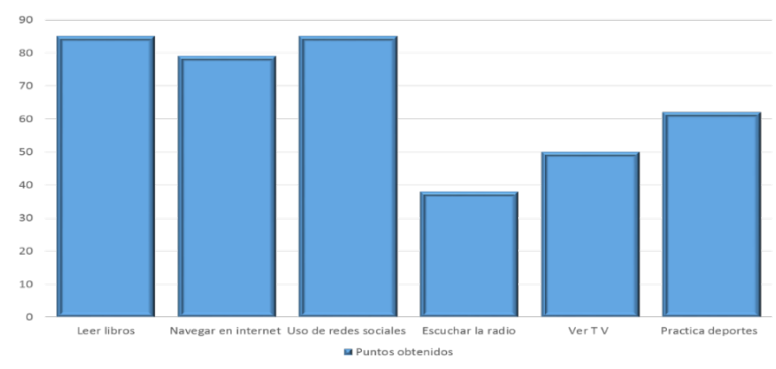

Fuente: Elaboración propia.

En el caso de los estudiantes de la MDPCP dedican tiempo a reuniones familiares en mayor medida, igualmente, al cine, a las reuniones con amigos, a acudir a cafés, conciertos, museos, festivales culturales, teatros, bares y por último a acudir a antros. Como puede observarse en la Gráfica 5. 
Grafica 5. Actividades recreativas MDPCP.

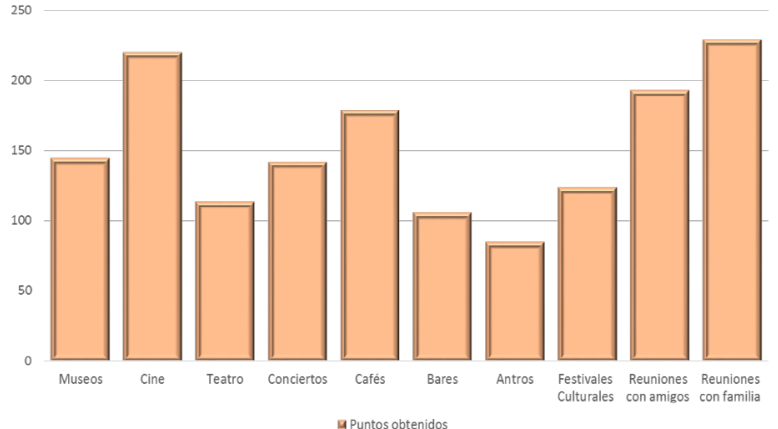

Fuente: Elaboración propia.

Como actividades en tiempo libre, los estudiantes de la MDPCP reportan que dedican tiempo a leer libros, navegar en internet, hacer uso de las redes sociales, ver TV, practicar deporte y por último escuchar la radio. Como puede observarse en la Gráfica 6.

Gráfica 6. Actividades tiempo libre MDPCP.

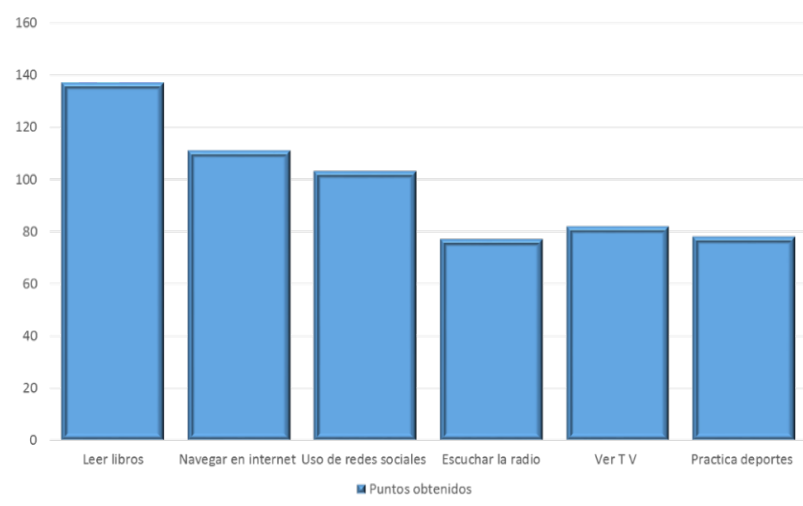

Fuente: elaboración propia.

\subsection{Capital social de los participantes}

Para identificar el capital social (la familia y amigos) por el cual pueden encontrarse estudiando derecho los estudiantes de la LD se puede observar que el $42.1 \%$ de los estudiantes cuentan con familia que ha estudiado la carrera de derecho, de los cuales un $57.14 \%$ son tíos y primos. A pesar de que el $42.1 \%$ ha estudiado la carrera de derecho, reportan que únicamente el $26.3 \%$ se encuentra ejerciéndola, esto quiere decir que el $73.7 \%$ no se encuentra ejerciendo el derecho a pesar de haberlo estudiado.

Del $26.3 \%$ que la ejerce, el $80 \%$ la ejerce en el ámbito privado, como postulantes particulares y el $40 \%$ en el ejercicio burocrático del derecho, es decir, existe un ejercicio compartido entre postular de forma privada (ejercicio liberal del derecho) y trabajar como servidor público (empleado jurídico). 
También se puede observar que el $54.89 \%$ de los estudiantes de la LD tienen amigos que estudiaron la carrera en derecho y la ejercen, el $81.81 \%$ en ejercicio privado y el $36.36 \%$ en ejercicio burocrático, siendo estos dos ámbitos los que se distinguen en el ejercicio del derecho en tanto el capital social más próximo de los estudiantes. Como puede observarse en la Figura 3.

Figura 3. Familia y amigos que se dedican al derecho LD.

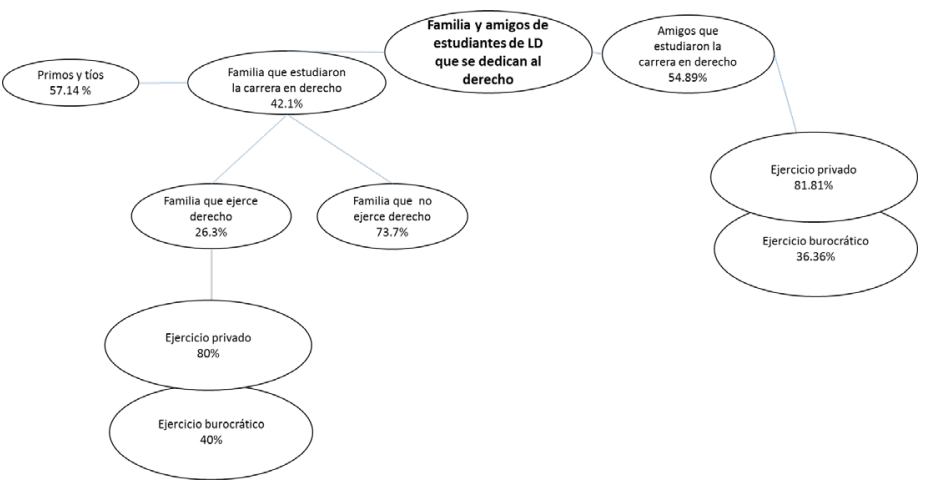

Fuente: elaboración propia.

De acuerdo con el capital social de los estudiantes de la MDPCP, el 57.14\% tiene familia que ha estudiado la carrera de derecho, de los cuales el 93.75\% ejerce jurídicamente, en mayor medida en el ámbito burocrático con un $73.33 \%$, en ejercicio privado $53.33 \%$ en ejercicio político con un $20 \%$ y el ejercicio docente con un $13.33 \%$.

También se identifica que el 100\% de estudiantes de la MDPCP tienen amigos que ejercen el derecho, el $82.14 \%$ en el campo burocrático, el $75 \%$ en ejercicio privado, el $75 \%$ en ejercicio docente, el $35.7 \%$ en ejercicio político y el $13.33 \%$ en ejercicio científico. Como puede observarse en la Figura 4.

Figura 4. Familia y amigos que se dedican al derecho MDPCP.

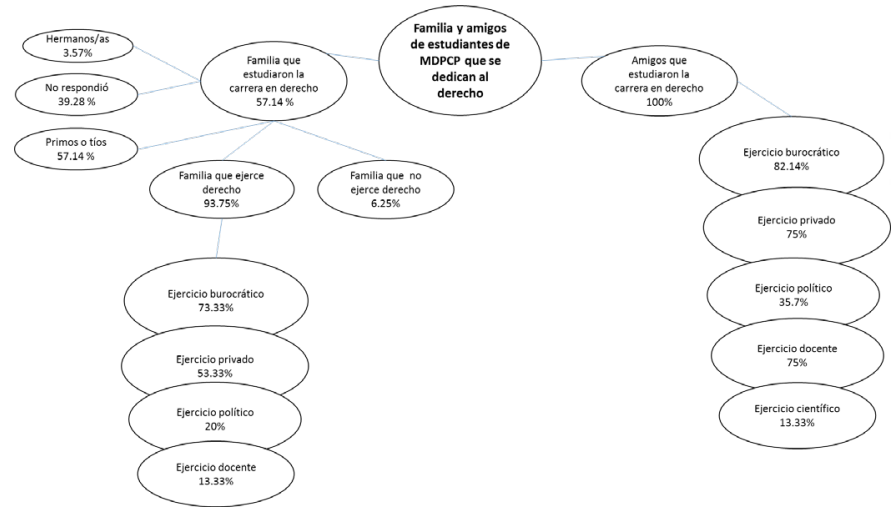

Fuente: Elaboración propia.

Con lo anterior se vislumbra que existe mayor capital social en el campo jurídico en la MDPCP, mayores redes sociales que permiten afianzarse en el campo, también se observa que en la formación de la LD solamente se mencionan dos ámbitos de ejercicio de derecho que son el 
ámbito de ejercicio privado y el burocrático, sin embargo, en la MDPCP se observa el campo político, docente y científico, con bajos porcentajes.

\section{3 Áreas de ejercicio profesional del derecho de acuerdo con los participantes}

Las actividades remuneradas a las que puede dedicarse un licenciado en derecho de acuerdo con lo que opinan los estudiantes de la LD, se plantearon tres opciones, como primera opción el ejercicio privado del derecho con un $78.9 \%$, posteriormente el ejercicio burocrático con un $15.7 \%$, el 5.26\% no respondió a la pregunta. Lo que puede observarse en la Figura 5.

Figura 5. Actividades remuneradas primera opción LD.

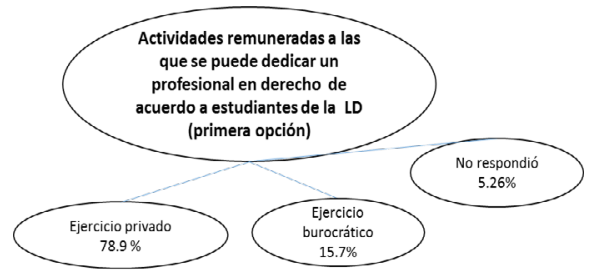

Fuente: Elaboración propia.

En el caso de estudiantes de la MDPCP se observa que la primera opción tiene tres ámbitos, el primero es el burocrático con un $64.28 \%$, el ejercicio privado con un $32.14 \%$ y ejercicio docente con un 3.57\%. Cabe hacer la distinción de que en la MDPCP aparece la opción docente, sin embargo, como primera opción no aparece para los estudiantes de la LD.

Figura 6. Actividades remuneradas primera opción MDPCP.

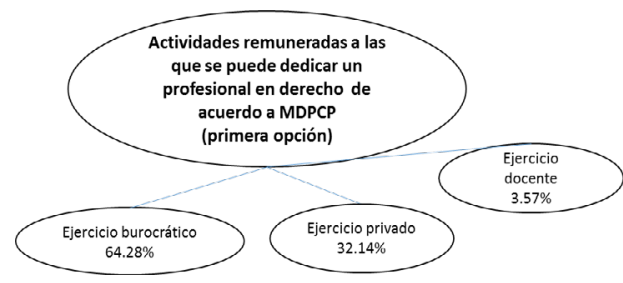

Fuente: Elaboración propia.

Los resultados anteriormente descritos responden a la aplicación de los cuestionarios en el campo durante el año 2019, en el siguiente apartado del artículo se discuten dichos resultados a la luz de la teoría sociológica bajo la cual se construyó la investigación.

\section{Discusión}

El análisis de resultados con base en la metodología bourdiana se lleva a cabo identificando los hallazgos detectados en el trabajo de campo, los registros de los cuestionarios y también los aspectos subjetivos que se profundizaron en las entrevistas semiestructuradas aplicadas desde la perspectiva social, contrastando dichos hallazgos con los conceptos principales de la teoría.

Lo anterior dado que la metodología complementaria permite dar cuenta de las estructuras 
objetivas, condiciones en las que tienen menor injerencia los agentes y también de las condiciones subjetivas, disposiciones de los agentes, de esta forma se obtiene más información del mismo campo social.

Como indican Blanco y Pirela (2016), la metodología complementaria genera un ambiente de superación con respecto a la dicotomía metodológica en la investigación social y hace el trabajo científico más exhaustivo y profundo.

Como se denotó en los resultados de la investigación, la mayoría de las mujeres en ambos subgrupos contrasta con el esquema tradicionalista y patriarcal del derecho como campo y mercado productor de capitales y disposiciones. El hecho de que no se hayan realizado transformaciones significativas en el campo al cambiarse las condiciones de sexo, siendo actualmente un campo productor preponderantemente femenino, lo que se relaciona con la significativa participación de las mujeres en el campo educativo y algunas transformaciones en las relaciones de género (Gastiazoro, 2013).

En la LD existe mayor participación de las mujeres, sin embargo, en ambos subcampos, la mayoría de las personas estudiantes son mujeres. El derecho parece establecerse todavía como un campo preponderantemente masculino debido a su trayectoria histórica en la cual ha sido propugnado y ejercido por hombres, también tomando en consideración que existen figuras jurídicas que devienen de la estructura patriarcal romana, especialmente en México. Para mostrar el análisis de los datos advertidos acerca de los capitales producidos y asimilados por estudiantes de la LD y la MDPCP se elaboró la Figura 7 en la cual se clasifican las disposiciones y los capitales de acuerdo con tres tiempos, la producción precedente, la producción en proceso y la producción a futuro.

Figura 7. Disposiciones y capitales asimilados por estudiantes de la LD y MDPCP.

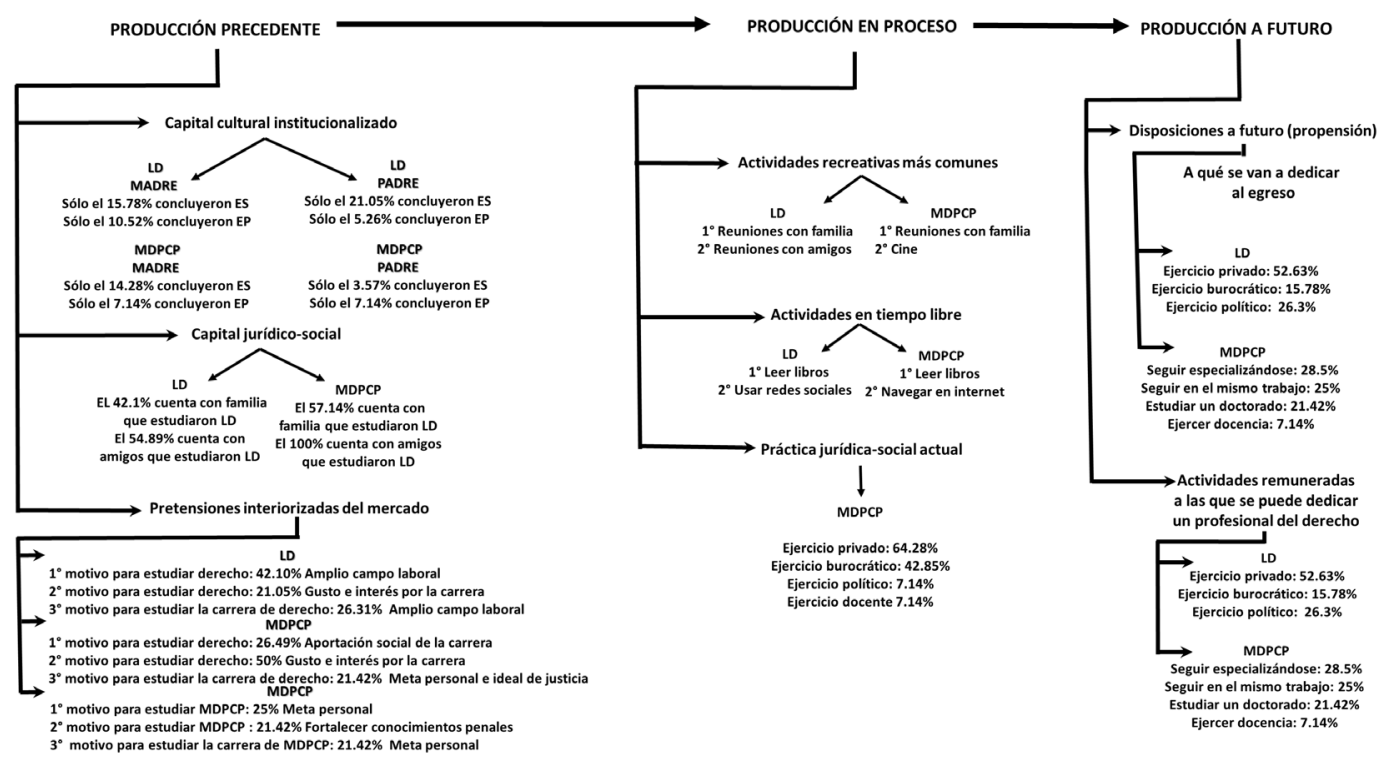

Fuente: Elaboración propia. 
Se encuentran los capitales y disposiciones que son herencia en los estudiantes, herencia por parte de sus padres, como es el caso del capital cultural institucionalizado, los estudiantes de la LD se identifica que solamente el $15.78 \%$ de las madres concluyeron la Educación Superior y únicamente el $10.52 \%$ cuentan con estudios de posgrado, en el caso de los padres, el $21.05 \%$ concluyeron Educación Superior y el 5.26\% estudios de posgrado, lo que significa que los estudiantes cuentan con un bajo capital cultural institucionalizado, sin embargo, se distinguen al encontrarse por concluir estudios en nivel Superior.

En el caso de los estudiantes del programa de Maestría en Derecho Penal y Ciencias Penales, se advierte que las madres, en un $14.28 \%$, concluyeron estudios superiores y un $7.14 \%$ cuenta con estudios de posgrado. Los padres poseen menor capital cultural institucionalizado debido que el $7.14 \%$ cuenta con nivel Superior y el 7.14\% cuenta con estudios de posgrado.

Otro de los registros significativos en los precedentes producidos es el capital jurídico-social con el que cuentan los estudiantes, en el caso de los estudiantes de la LD, el 42.1\% cuenta con familia que estudió la carrera profesional de derecho y un 54.89\% tienen amigos que se formaron en el campo del derecho. En el caso de los estudiantes de la MDPCP el 57.14\% cuenta con familia que ha estudiado en el campo del derecho y el 100\% cuenta con amigos que estudian derecho.

Los motivos para estudiar derecho son producciones precedentes al ingreso a estudiar la carrera profesional, el primer motivo para estudiantes de la LD implica el amplio campo laboral (42.10\%), en el segundo motivo refirieron el gusto e interés por la carrera con un (21.05\%) y como tercer motivo nuevamente el amplio campo laboral (26.31\%). En el caso de la MDPCP el primer motivo es la aportación social de la carrera (26.49\%), el segundo motivo es el gusto e interés por la carrera (50\%) y el tercer motivo es como una meta personal (21.42\%).

Lo anterior devela la forma en que los estudiantes interiorizaron ciertos pensamientos o imágenes mentales de la carrera de derecho, de su campo, principalmente en la LD el campo laboral amplio y en el caso de la MDPCP la imagen de que la carrera ayuda socialmente.

Los motivos por los que los estudiantes de la MDPCP estudiaron la maestría, son, en primer lugar, como una meta personal (25\%), para mejorar sus conocimientos en la materia penal (21.42\%) y como tercer motivo nuevamente como meta personal (21.42\%). Evidentemente los agentes que estudian la MDCPC conservan de forma más firme la inculcación de disposiciones y capitales del campo y muestran su interés personal por el campo de forma más enfática e involucrada.

Como se puede advertir en la figura 8, los estudiantes de la LD no expresan que pueden dedicarse a la investigación, es decir, tienen menor intención científica, traducida esta como disposición. Sin embargo, en el caso de los estudiantes de la MDPCP expresan verbalmente que tienen la intención de dedicarse al campo científico-jurídico, no obstante, no se encuentran ejerciendo el derecho en ese ámbito ni han tenido un contacto profundo con la investigación jurídica. 
Figura 8. Intención científica

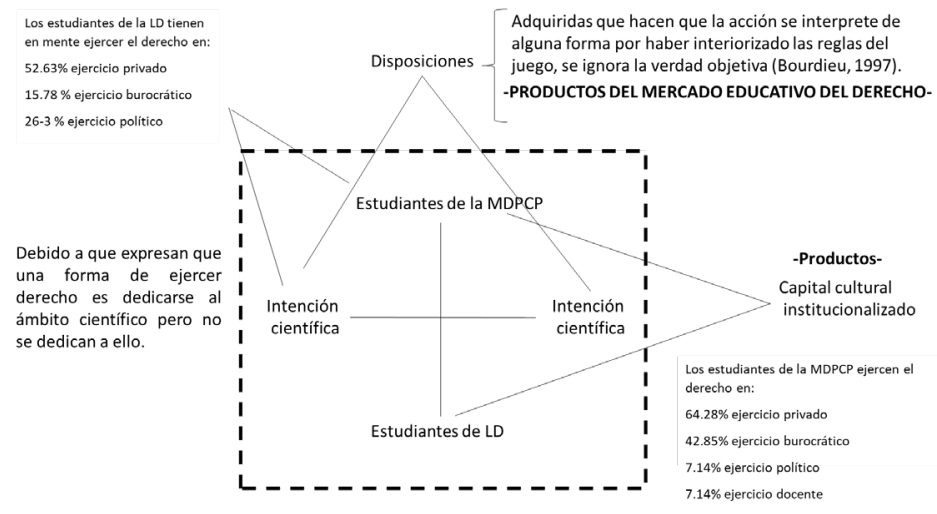

Fuente: Elaboración propia.

Los estudiantes de la MDPCP muestran que advierten, de forma discursiva, que pueden dedicarse a la investigación jurídica, en primera opción con un 3.57\%, en segunda opción con un $10.71 \%$ y como tercera opción con un 7.14\%, sin embargo, al cuestionarles las actividades que realizan como egresados de la Licenciatura en Derecho, no refieren dedicarse o mostrar práctica científicojurídica. En el caso de los estudiantes de la LD, no refieren siquiera la posibilidad de dedicarse a investigar jurídicamente como egresados de la licenciatura que estudian.

Otro aspecto que se advierte dentro de los subcampos indagados, la MDPCP y la LD, ambos grupos expresan que estudian derecho o han decidido esta carrera debido a la importancia que tienen con respecto a la aportación social que la carrera les permite tener, la forma en que pueden ayudar socialmente a las causas más desatendidas, sin embargo, no explicitan aquello cuando se les pregunta por las actividades que desean llevar a cabo al egresar del programa de formación jurídica que estudian. Lo anterior puede observarse en la Figura 9.

Figura 9. Aportación social

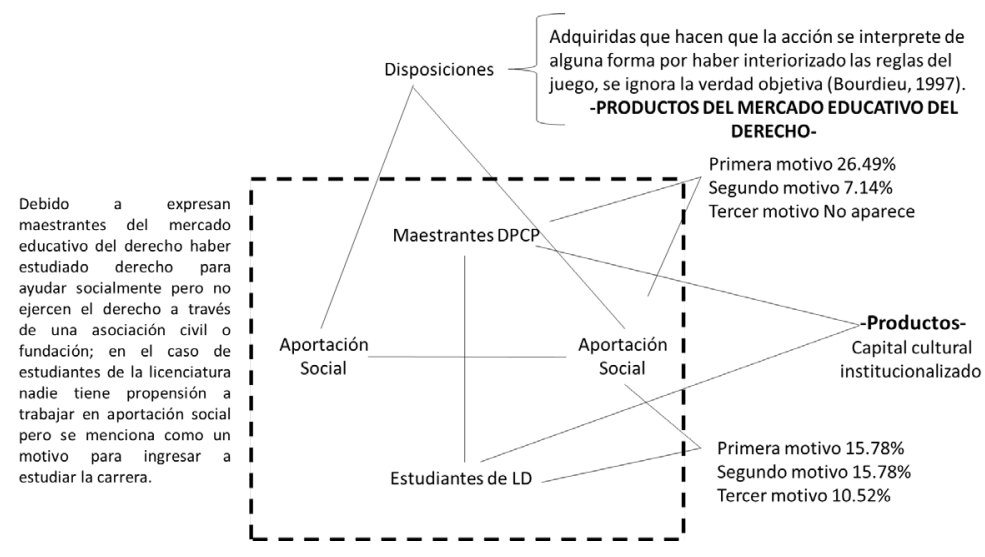

Fuente: Elaboración propia. 
La aportación social de la profesión jurídica es altamente vinculante desde la trayectoria histórica de esta, se reconoce la importancia de generar consciencia social para atender sectores sociales problemático (Vázquez, 2012) por ello puede ser parte de su formación educativa pero no necesariamente de sus acciones laborales o intenciones reales, esto también considerando que el mercado laboral ofrece mayor crecimiento en otros ámbitos de ejercicio del derecho (Gómez, 2016).

En la Figura 10 se muestran las posiciones producidas en el mercado del derecho en egresados del campo, existen tres posiciones laborales distinguibles, quienes ejercen liberalmente el derecho, quienes ejercen el derecho como empleados y una posición híbrida, agentes que se dedican al ejercicio liberal del derecho y a la docencia, como empleados institucionales por asignatura.

Los agentes que ejercen el derecho como profesión liberal se distinguen por poseer intereses focalizados en el éxito de su profesión como profesionistas autónomos, asimismo se encuentran desinteresados en otras áreas de conocimiento, inclusive en áreas de ciencias sociales, conservan nociones tradicionalistas del derecho, mayor práctica, pero menos intención jurídica, menor idealización del derecho como reglador neutral y más interés en las soluciones heterónomas. Estos agentes que ejercen el derecho de forma liberal muestran disposiciones lúdicas dentro del campo, es decir son producidos cumpliendo el objetivo tradicional del ejercicio jurídico, se encuentran adecuados al campo del derecho en el cual fueron formados.

También se aprecia cómo la producción asimilada en agentes que ejercen el derecho dentro de un sistema institucional ya sea en el ámbito burocrático, en el docente o el científico, poseen nociones tradicionalistas del derecho, sin embargo, tienen más intención jurídica, mayor idealización del derecho como regulador neutral, y menos práctica jurídica porque no se encuentran inmersos en soluciones heterónomas.

Las disposiciones mostradas de estos segundos agentes son de resignadas a heréticas, se encuentran inadecuados conforme el campo en el que se producen, se resignan ante un rol no tradicional del derecho o poseen críticas e inconformidades del campo del derecho en el ICSHu de la UAEH.

Ambos agentes descritos en los párrafos anteriores develan el efecto histéresis, que propone Bourdieu, puesto que llevan a cabo prácticas fijadas en el pasado, aunque las necesidades actuales no corresponden. Este efecto de histéresis se transmite como un valor alto dentro de este mercado del derecho.

El tercer agente, que se denomina híbrido social, ejerce liberalmente el derecho, sin embargo, se encuentra siendo empleado en la docencia de la institución que los produjo, específicamente en el Área Académica de Derecho y Jurisprudencia del ICSHu. Dichos agentes muestran mayor dedicación en tiempo y atención al trabajo como profesionistas liberales, sin embargo, hacen uso del capital docente para insertarse en el sistema institucional. 
Figura 10: Posiciones laborales en el mercado educativo del derecho.

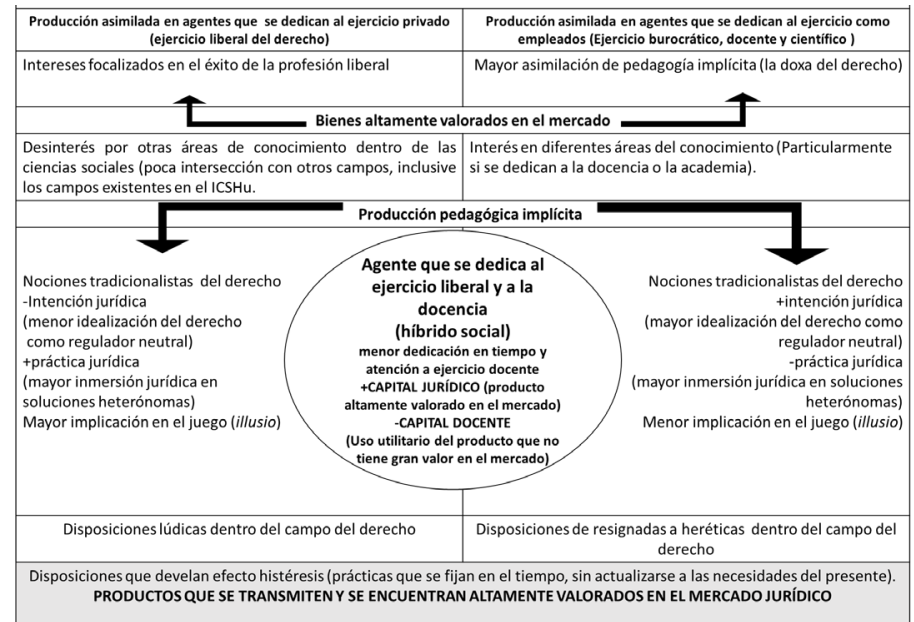

Fuente: Elaboración propia.

El análisis con herramientas teóricas arroja algunas características que distinguen a estas tres clases de agentes, por un lado se aprecia que quienes ejercen como empleados, poseen visión tradicional del derecho pero esto, no corresponde a las condiciones objetivas, es decir, encontrarse ligado a una institución que dirige sus acciones, asimismo se advierten disposiciones de resignadas a heréticas, sus actitudes muestran inconformidad del rol jurídico actual y un mayor contacto con otros campos del conocimiento, la educación, la docencia, la admiración y demás ciencias sociales.

Las áreas de oportunidad de la investigación que se presenta en este artículo indican una metodología diversa que incluya Análisis de Correspondencias Múltiples que describa mejor el campo investigado. Otro aspecto para enriquecer el estudio podría configurarse con la profundización en las trayectorias sociales de los IC.

Derivado de la investigación realizada, se encuentra en construcción un estudio que considera los capitales burocráticosy masculinos que se advirtieron en el mercadojurídico del ICSHu, para indagar las características objetivas y subjetivas de la realidad social en el Tribunal Superior de Justicia del Estado de Hidalgo, institución con trayectoria histórica desde 1989 y que preponderantemente ha sido alimentada por egresados de la UAEH, del Área de Derecho y Jurisprudencia.

El mundo jurídico, en su trayectoria histórica y social, se presenta de forma diferente ante las mujeres y los hombres, las mujeres no han ocupado espacios de toma de decisiones, de dirección y los hombres son quienes, comúnmente se posicionan en puestos jerárquicos altos.

En México, las mujeres no han tenido una inserción rápida en el mundo del derecho, comenzaron a involucrarse en trabajos como atención a la salud, educación básica y especialidades médicas de obstetricia y no a posiciones políticas o jurídicas (Chávez, 2010).

En las profesiones jurídicas, desde los años 1960, las mujeres se han incorporado de forma radical, actualmente, en posiciones jurídicas, las mujeres alcanzan el 50 por ciento de los puestos (Schultz, 1993). 
En el Tribunal Superior de Justicia del Estado de Hidalgo se encuentra un ejemplo de la inmersión de las mujeres al campo jurídico-institucional, aunque no por ello, necesariamente, esto genera igualdad sustantiva entre hombres y mujeres. El caso particular de la institución indica que entre los funcionarios y las salas hay 22 mujeres de 30 posiciones en total.

Para identificar algunos datos históricos relevantes del campo de investigación, el Tribunal Superior de Justicia ha sido mayoritariamente presidido por hombres, sin embargo, desde 2006 comenzó a ser presidido por mujeres, únicamente han sido 3 mujeres presidentas, en el periodo de 2006 al 2009 lo presidió Alma Carolina Viggiano Austria y del periodo comprendido entre el 2016 y el año 2020 Blanca Sánchez Martínez. Actualmente la institución se encuentra presidida por Yanet Herrera Meneses desde el 8 de noviembre de 2020. Asimismo, es sumamente notoria la presencia de las mujeres en diversos puestos en la institución, aun así, el supuesto de la investigación en proceso indica que la sola presencia de las mujeres no genera cambios en cuanto a la dominación masculina, debido a que los agentes del campo siguen los patrones instaurados para conservar la tradición del derecho.

\section{Conclusión}

La investigación realizada pone de manifiesto que el campo jurídico no ha sido abordado a profundidad desde una perspectiva crítica, este abordaje permitiría generar reflexiones con mayor profundidad en cuanto al funcionamiento de este en la actualidad. En el campo del derecho existen más investigaciones elaboradas conforme revisiones teóricas que, en ocasiones, repiten lo establecido por las teorías jurídicas clásicas.

La construcción de posturas científicas que inviten a mirar analíticamente al campo jurídico puede intervenir de manera favorable para transformar las concepciones jurídicas absolutistas y mejorar las condiciones de producción de agentes que ejercen el derecho desde diferentes frentes.

El uso del entramado teórico bourdiano permite caracterizar a detalle la producción de capitales y disposiciones en el campo de investigación, sin restringir o tasar al área como homogénea, permite concebir la realidad social (en este caso jurídica) como una composición compleja, en la cual se encuentran elementos ordenados de acuerdo con una lógica interna específica que indica las reglas de funcionamiento y distinción de otros campos.

El capital, desde la teoría de la Economía de las Prácticas Sociales, es un eje rector de la investigación social que posibilita descubrir qué disposiciones son de importancia para el campo, conociendo, a su vez, las posiciones y también las prácticas más valoradas. El uso de la metodología bourdiana implica aproximarse al campo desde sus componentes objetivos (las condiciones institucionales, las posiciones del campo, etc.) y en un segundo momento profundizar en las percepciones de los agentes (formas de mirar la realidad interiorizadas, formas de pensar, de sentir y de mostrarse) para conocer el punto de vista desde el que miran el mundo social. 
En el campo jurídico se advierten peculiaridades interesantes como sistema social macro, se reconoce como un sistema hermético y prescriptivo que se regula a sí mismo y de la misma manera regula con su normativa a los demás campos. En el contexto específico de la investigación se han advertido ciertas condiciones que coadyuvan a la comprensión de la dinámica de producción de recursos o capitales dentro del campo.

La investigación descrita en el desarrollo del artículo y la que se encuentra en proceso, trabajan de la mano para analizar un campo social de gran tradición y por lo mismo, de poca transformación que, a través de la formación, continúa ejerciendo el poder social desde estructuras sociales más grandes con gran fuerza simbólica.

Algunos obstáculos al construir la investigación radican en la amplitud del campo del derecho y la selección de participantes, se pudo tomar en cuanta una mayor cantidad de participantes e inclusive considerar participantes con características diversas como profesionistas liberales de la profesión o académicos del derecho.

Se considera de importancia que las investigaciones similares a la que se presenta en este articulo asistan a teóricas críticas del derecho y a realidades empíricas diferentes como espacios gubernamentales del ejercicio jurídico o asociaciones sin fines de lucro que ejercer el derecho para conocer las características que orientan su actuar y motivaciones como agentes del mercado jurídico. Igualmente se puede hacer uso de las metodologías más sistemáticas como el Análisis de Correspondencias Múltiples (ACM).

\section{Referencias}

Becerra, K. (2020). Investigación cualitativa crítica y derecho: análisis de su rol en la academia chilena y un estudio de caso. Revista Pedagogía Universitaria y Didáctica del Derecho, 7(1), 149-176. http://doi. org/10.5354/0719-5885.2020.55375

Blanco, N., y Pirela, J. (2016). La complementariedad metodológica: Estrategia de integración de enfoques en la investigación social. Espacios públicos, 19(45), 97-111. https://cutt.ly/rYEFYQV

Bourdieu, P., y Passeron, J. C. (2017). La Reproducción: elementos para una teoría del sistema educativo. Siglo XXI Editores.

Bourdieu, P. (2011) Capital cultural, escuela y espacio social. Siglo XXI.

Bourdieu, P., Chamboredon, J. C., y Passeron, J. C. (2002). El oficio del sociólogo. Siglo XXI.

Bourdieu, P. (1993). Génesis y estructura del campo burocrático. Actes de la recherche Sciences Sociales, 9697, $49-62$

Chávez, M. (2010). Trabajo femenino, las nuevas desigualdades. Universidad Nacional Autónoma de México. Instituto de Investigaciones Económicas.

Gastiazoro, M. E. (2013). Género y trabajo: mujeres en el Poder Judicial. Universidad Nacional de Córdoba.

Gómez, G. (2016). ¿Abogados para la democracia o para el mercado? Repensar la educación jurídica. Revista de derecho, (46), 225-256. http://dx.doi.org/10.14482/dere.46.8817

Merino, R. (2017). El Derecho como campo de crítica y poder. La política de la teoría legal desde América Latina. Derecho \& Sociedad, (48), 225-254. 
Moreno, A., Sandoval Mesa, J., Torregrosa Jiménez, N., y Torregrosa Jiménez, R. (2019). El campo jurídico híbrido en la justicia transicional en Colombia. Revista republicana, (27), 89-104. http://dx.doi. org/10.21017/Rev.Repub.2019.v27.a68

Moyano, P. (2020). El dispositivo del poder en el derecho. Entre Enrique Marí y Pierre Bourdieu. Revista Argumentos. Estudios Transdisciplinarios sobre Culturas Jurídicas y Administración de Justicia, (11), 13-25. https://revistaargumentos.justiciacordoba.gob.ar/index.php/primera/article/view/178

Rosa, P. (2009). La ciencia que se está haciendo: Reflexiones metodológicas de la mano de Pierre Bourdieu. Kairos Revista de temas sociales, 13(24), 1-8. https://cutt.ly/kYEHVDL

Pezzetta, S. (2016). Pierre Bourdieu y Basil Bernstein: aportes para la investigación sobre las facultades de Derecho. CPU-e. Revista de Investigación Educativa, (22), 120-150. https://doi.org/10.25009/cpue. voi22.1944

Schultz, U. (1993). Gender in Socio-Legal Teaching and Research in Germany. German Law Journal, 21(7), 1345-1361 https://doi.org/10.1017/glj.2020.86

Torres, A., y Jiménez, A. (2006). La construcción del objeto y los referentes teóricos en la investigación social. En A. Jiménez Becerra y C. A. Torres (Comp.). La Práctica Investigativa en Ciencias Sociales. (pp. 15-28). Universidad Pedagógica Nacional

Vázquez, R. (2012). El rol de los abogados en el estado social de derecho: Tendencias y perfiles contemporáneos. Jurídicas CUC, 8(1), 137-171. https://revistascientificas.cuc.edu.co/juridicascuc/ article/view/436

Wolkmer, A. C. (2019). Teoría crítica del derecho desde América Latina. Ediciones Akal.

\section{AUTORES}

Claudia Valeria Zúñiga Manríquez. Doctorante en Ciencias Sociales y Máster en Ciencias de la Educación.

Armando Ulises Cerón Martínez. Doctorado en Pedagogía por la Universidad Nacional Autónoma de México. Maestría en Filosofía de la Ciencia por la Universidad Autónoma Metropolitana. Profesor Investigador de Tiempo Completo en la Universidad Autónoma del Estado de Hidalgo. 